\title{
O surgimento da pesquisa em Jornalismo de Dados no Brasil
}

\section{Jessica Bazzo}

Mestra; Universidade Federal de Goiás, Goiânia, GO, Brasil

jessicabazzo.jor@gmail.com

\section{Dalton Lopes Martins}

Doutor; Universidade de Brasília, Brasília, DF, Brasil

dmartins@gmail.com

\section{Filipe Augusto Couto Barbosa}

Doutorando; Universidade Federal de Goiás, Goiânia, GO, Brasil scientificfil@gmail.com

\section{Resumo}

Este trabalho é uma revisão sistemática de artigos, dissertações e teses sobre Jornalismo de Dados publicados no Brasil e tem o objetivo de mapear os principais estudos, abordagens, autores, grupos, projetos e instituições articulados em torno do tema. Os resultados indicam que os estudos e pesquisas sobre o tema são incipientes e recentes no Brasil (o primeiro estudo data de 2007) e que ganharam maior relevância atualmente, registrando-se um importante aumento no número de publicações qualificadas nos anos de 2016 e 2017. Além disso, identificam-se autores e instituições que se colocaram como pioneiros do tema no país, dando os primeiros passos para consolidar o Jornalismo de Dados como subcampo científico do Jornalismo e, portanto, da Comunicação.

\section{Palavras-chave}

Jornalismo de Dados. Jornalismo Guiado por Dados. Jornalismo Digital.

\section{Introdução}

As possibilidades advindas com as mídias digitais e com as revoluções na Web têm modificado bastante o fazer jornalístico, e, com tanta informação disponível publicamente (seja em bases de dados on-line, blogs jornalísticos ou portais de notícias, seja nas mídias sociais, sites e fonte digitais em geral), dominar conhecimentos que favoreçam a extração, a curadoria e a exposição inteligível de dados em plataformas de comunicação se tornou uma exigência para o jornalista. Atualmente, este profissional tem de coletar e selecionar dados digitais brutos, tratá-los e interpretá-los e ainda criar modelos interativos e simples de 
visualização, para, somente então, compor a narrativa atraente, estruturada e relevante de uma notícia - o que era a sua função original.

Essa demanda por um fazer jornalístico que consiga mediar dados de interesse e relevância públicos no aparente mar de informação que se apresenta com a globalização conectada por internet tem evidenciado certa modalidade de produzir notícias, a saber: o Jornalismo de Dados. O Jornalismo de Dados não é novo, e, embora o termo comece a ser utilizado apenas na década de 2000, deriva de outros subcampos do Jornalismo, como o Jornalismo de Precisão, proposto por Philip Meyer, ou como a Reportagem Assistida por Computador (RAC), que tem raízes no Jornalismo Investigativo.

Segundo Paul Bradshaw, em sua participação no Manual de Jornalismo de Dados 1.0 (GRAY; BOUNEGRU; CHAMBERS, 2014), o Jornalismo de Dados surgiu com o uso de software para automatizar o trabalho de combinar informações, filtrar dados em documentos e criar modelos para sua visualização, o que teria propiciado matérias jornalísticas mais completas, com formatos mais atrativos e com dados de interesse dos cidadãos. Nesta modalidade, por vezes, trabalha-se com dados em uma escala tratável apenas por computadores (Big Data), visando a sua exposição e/ou sua visualização de forma a facilitar a compreensão por leigos, dentro de uma narrativa jornalística atraente e com pautas de relevância social.

Assim, além da articulação de vários saberes já integrados ao Jornalismo em pautas relevantes, impõem-se desafios técnicos envolvendo a utilização de novos tipos de dados sociais e de fontes on-line e a atualização constante de dispositivos, softwares e mídias, em um processo de trabalho nem sempre passível de se concentrar em um único profissional, organizando-se em redes de colaboração e equipes interdisciplinares de vários formatos (incluindo, por exemplo, programadores e designers). Dentre outros aspectos, o Jornalismo de Dados tem se destacado por ajudar os cidadãos das democracias do mundo a fiscalizarem seus governos, ampliando os mecanismos de accountability.

Essas mudanças no cotidiano da produção jornalística e a apropriação do Jornalismo de Dados como ferramenta de promoção da cidadania e da democracia na era da internet têm chamado a atenção da comunidade acadêmica mundial, em especial, de pesquisadores do campo da Comunicação, mas também da Ciência da Informação e da Ciência Política. No Brasil, publica-se a primeira pesquisa densa sobre o assunto em 2007, verificando-se, nesta última década e com cada vez mais frequência, outras iniciativas e um aumento notável da produção científica em 2016 e 2017, com artigos, dissertações e teses sobre o tema.

Diante desse quadro, justifica-se uma revisão sistemática da produção qualificada relativa ao Jornalismo de Dados no Brasil, tal qual a que aqui realizamos. A presente revisão se atém aos artigos publicados nos periódicos científicos brasileiros de maior impacto para o 
campo da Comunicação e a dissertações e teses publicadas em bases de dados oficiais. 0 objetivo foi levantar dados das publicações e pesquisas sobre Jornalismo de Dados (como as principais temáticas e abordagens metodológicas), identificando autores, grupos, projetos de pesquisa e universidades articulados em torno do tema.

\section{Metodologia}

A presente revisão objetiva estabelecer um panorama de como a pesquisa científica relativa ao Jornalismo de Dados está se desenvolvendo no Brasil, e isso tendo em conta os periódicos mais bem avaliados devido ao seu fator de impacto no campo da Comunicação e também as dissertações e teses publicadas em bases de dados oficiais do país. Ainda que não seja uma revisão total do que se publicou sobre o assunto, este recorte possibilita trabalhar com a produção mais influente sobre o campo.

No caso dos artigos, utilizou-se a avalição do Qualis Periódicos para a seleção das revistas. Tal avaliação é feita por cientistas qualificados, e ligados a Instituições de Ensino Superior (IES) brasileiras, convocados pela Coordenação de Aperfeiçoamento de Pessoal de Nível Superior (CAPES). Os conceitos da avaliação buscam estimar o alcance e o fator de impacto atual das publicações de pesquisadores vinculados a IES brasileiras e não ranquear periódicos em si; quais sejam: A1 (maior impacto), A2, B1, B2, B3, B4 e C (menor impacto) conceitos referentes à classificação de periódicos do quadriênio 2013-2016, na Plataforma Sucupira da CAPES, vigorante para as avaliações no quadriênio seguinte (2017-2020).

Já as dissertações e teses foram selecionadas confrontando os dados de dois bancos digitais: a Biblioteca Digital de Teses e Dissertações (BDTD), ligada ao Instituto Brasileiro de Informação em Ciência e Tecnologia (IBICT), e o Catálogo de Teses e Dissertações da CAPES.

A seleção para esta revisão contemplou a produção de maior impacto, ou aquela já referendada oficialmente e que detém o "capital científico" no "campo" (BOURDIEU, 1983) da Comunicação. Então, com a avaliação dos periódicos pela CAPES (e pelos revisores destes para cada artigo aceito) e com a avaliação das bancas de mestrado e doutorado no caso das dissertações e teses, obtém-se legitimidade científica, sendo os seus autores reconhecidos como competentes por sua comunidade de pares, ou seja, os cientistas já estabelecidos no campo da Comunicação. Com isto, não se propõe um estudo crítico das práticas científicas no campo da Comunicação no Brasil, mas um parâmetro qualitativo para uma amostra, que não se pretende uma representação matemática de toda a produção sobre o Jornalismo de Dados no país, mas uma representação sociológica dessa produção, que indica as tendências nesse campo científico. 


\subsection{Recorte na revisão de artigos}

Optou-se pelos artigos publicados em periódicos científicos ligados a instituições do Brasil e que obtiveram conceitos Qualis A1, A2 e B1 da Área de Avaliação em Comunicação e Informação da CAPES (quadriênio 2013-2016). Dentre estes, apenas os periódicos ligados explicitamente ao campo da Comunicação foram considerados, o que se deduziu a partir de análise de título e escopo. Quarenta e quatro (44) periódicos foram considerados para esta análise, sendo encontrados oito (8) artigos - ressalta-se ainda que esta análise considerou artigos publicados até julho de 2018, devido à época da coleta de dados para a revisão.

Os sites dos periódicos selecionados foram acessados um a um, e na ferramenta de busca por conteúdo, utilizou-se a palavra-chave Jornalismo de Dados, restringindo-se os resultados àqueles estudos em que a expressão figura no título, resumo ou palavras-chave, entendendo-se que a ocorrência da referida expressão em algum desses campos indexados indicaria que o tema seria trabalhado com destaque no artigo.

A análise visou levantar possíveis usos conceituais e instrumentais do Jornalismo de Dados e identificar as abordagens metodológicas, os principais autores, suas instituições de origem, o período das publicações e as palavras-chave relacionadas, formando um conjunto básico de dados qualitativos e quantitativos sobre essa produção.

\subsection{Recorte na revisão de dissertações e teses}

Na busca pela palavra-chave Jornalismo de Dados na BDTD do IBICIT e no Catálogo de Teses e Dissertações da CAPES (que utiliza dados da Plataforma Sucupira), em coleta realizada entre agosto e outubro de 2017, foram encontradas sete (7) dissertações, as quais têm orientadores distintos, provêm de diferentes universidades e, por região, apresentam a seguinte distribuição: três (3) da Região Sul, três (3) da Região Sudeste e uma (1) da Região Nordeste; e, em coleta ocorrida entre agosto e novembro de 2017, encontraram-se seis (6) teses, as quais têm orientadores distintos, são de diferentes universidades e, por região, apresentam a seguinte distribuição: três (3) da Região Sudeste, duas (2) da Região Sul e uma (1) da Região Nordeste.

A análise visou identificar: o período de produção, as abordagens metodológicas das pesquisas, outros temas a que estariam relacionadas e autores e/ou instituições articulados em torno do Jornalismo de Dados. Reunir essas informações possibilita compreender como está se consolidando este subcampo do Jornalismo na academia, de que perspectivas e sob quais desafios. Enquanto trabalhos finais de cursos em nível de pós-graduação stricto sensu, 
as dissertações e teses refletem tempo e qualidade dedicados à pesquisa sobre o tema e a mobilização de programas de pós-graduação ao endossar tais estudos e ao instituir linhas de pesquisa que os acolhessem.

\section{Artigos sobre Jornalismo de Dados}

No total, seguindo-se a metodologia descrita na seção anterior, tem-se que foram explorados quarenta e quatro (44) periódicos, e foram encontrados artigos sobre Jornalismo de Dados em oito (8), sendo que um (1) artigo em cada periódico.

Na Tabela 1, tem-se a relação dos periódicos e de seus respectivos números de ISSN e conceitos Qualis Periódicos da CAPES na Área de Avaliação em Comunicação e Informação, bem como o número de artigos sobre Jornalismo de Dados encontrados em cada periódico.

Tabela 1 - Periódicos de Comunicação que publicaram artigos sobre Jornalismo de Dados

\begin{tabular}{cccc} 
ISSN & Periódicos & Qualis & No de artigos \\
\hline $1808-4079$ & Brazilian Journalism Research & A2 & 1 \\
$1808-2599$ & E-compós & A2 & 1 \\
$1519-311 X$ & Galáxia & A2 & 1 \\
$2175-7755$ & Comunicação \& Sociedade & B1 & 1 \\
$1809-9386$ & Contemporânea & B1 & 1 \\
$1807-8583$ & Intexto & B1 & 1 \\
$1807-1236$ & Organicom & B1 & 1 \\
$1984-8226$ & Revista Fronteira & B1 & 1 \\
\hline
\end{tabular}

Fonte: Dados da pesquisa.

Nota-se que três (3) dos artigos foram encontrados em periódicos qualificados no estrato A2, e cinco (5) no estrato B1. A ausência de artigos sobre Jornalismo de Dados no estrato A1 pode indicar que a discussão sobre esse tema ainda não alcançou o status das temáticas mais proeminentes entre os círculos dominantes no campo da Comunicação, mas a sua presença nesses outros dois estratos, embora ainda tímida, já significa que o tema tem adquirido maior relevância, com tendência ao crescimento - o que ficará evidente na série histórica (vide seção 3.2 deste artigo). 


\subsection{Autores e instituições}

Dentre os oito (8) artigos encontrados, seis (6) são frutos de trabalho em coautoria. Para identificar autores e coautores, utilizaram-se letras (vide Quadro 1); desta forma, por exemplo, o autor principal do artigo identificado com o código $A$ tem coautores identificados também com o código $A$.

Na amostra, foi possível identificar apenas uma autora com mais de uma publicação: a professora Luciana Mielniczuk, da Universidade Federal do Rio Grande do Sul (UFRGS), no caso, um artigo - como autora principal (MIELNICZUK; TRÄSEL, 2017) - e uma entrevista - com Philip Meyer (2017), enquanto segunda entrevistadora, junto a Marília Gehrke.

Pode-se visualizar no Quadro 1 a distribuição dos autores de acordo com seu vínculo institucional e também as coautorias, tendo sido identificados um total de quatorze (14) autores e coautores, sendo que dois (2) artigos foram produzidos por apenas um autor, cinco (5) em duplas e um (1) em trio. Observou-se diálogo entre instituições nas coautorias em apenas dois (2) casos. Dois (2) dos artigos envolvem autores estrangeiros, totalizando três (3) autores estrangeiros com participação nestes, e onze (11) brasileiros nos demais. Entre os estrangeiros, têm-se duas (2) autoras vinculadas a instituições francesas e um (1) a uma instituição estadunidense. Entre os brasileiros, seis (6) têm vínculo com IES da Região Sudeste, sendo quatro (4) de São Paulo e duas (2) do Rio de Janeiro, três (3) com IES da Região Sul (todos do Rio Grande do Sul) e dois (2) com IES da Região Nordeste (ambos da Bahia) - sendo três (3) autores vinculados a duas (2) universidades brasileiras cada, e um (1) autor a duas (2) universidades da Espanha e a uma (1) brasileira, somando três (3) no total, caso ímpar de Denis Porto Renó (vide Quadro 1).

Quadro 1 - Autores e instituições ligados aos artigos

\begin{tabular}{|l|c|}
\hline \multicolumn{1}{|c|}{ Autores } & Instituições \\
\hline BARBOSA, Suzana Oliveira. Autora Principal A & UFBA \\
\hline TORRES, Vitor. Coautor A & UFBA \\
\hline MANCINI, Leonardo. Autor principal B & ESPM/RJ \\
\hline VASCONCELLOS, Fabio. Coautor B & ESPM/RJ e UERJ \\
\hline RENÓ, Luciana. Autora principal C & USP e Unesp \\
\hline RENÓ, Denis Porto. Coautor C & Unesp, USC e UCM \\
\hline
\end{tabular}




\begin{tabular}{|l|c|}
\hline CORRÊA, Elizabeth Saad. Coautora C & USP \\
\hline GEHRKE, Marília. Autora principal D & UFRGS \\
\hline MIELNICZUK, Luciana. Coautora D & UFRGS \\
\hline CHARBONNEAUX, Juliette. Autora principal E & Sorbonne (FR) \\
\hline GKOUSKOU-GIANNAKOU, Pergia. Coautora E & Clermont Auvergne (FR) \\
\hline MIELNICZUK, Luciana. Autora principal F & UFRGS \\
\hline TRÄSEL, Marcelo. Coautor F & UFRGS \\
\hline ZIBORDI, Marcos Antônio. Autor G & USP e FCL \\
\hline RADCLIFFE, Damian. Autor H & UO (EUA) \\
\hline
\end{tabular}

Fonte: Dados da pesquisa.

Entre as IES, destacam-se as participações da UFRGS e da Universidade de São Paulo (USP), com três (3) pesquisadores cada; da Escola Superior de Propaganda e Marketing (ESPM/RJ), da Universidade Federal da Bahia (UFBA) e da Universidade Estadual Paulista (Unesp), com dois (2) pesquisadores cada; e, com apenas um (1) pesquisador, destacam-se as participações da Universidade Estadual do Rio de Janeiro (UERJ), da Faculdade Casper Líbero (FCL), das universidades francesas Sorbonne e Clermont Auvergne, da Universidade de Santiago de Compostela (USC) e da Universidade Complutense de Madrid (UCM), ambas da Espanha, e, dos Estados Unidos da América (EUA), da Universidade de Oregon (UO). No quesito número de artigos, UFRGS e USP se destacam de novo, tendo cada qual se vinculado a dois (2) artigos, enquanto que todas as outras instituições a apenas um (1).

\subsection{Série histórica}

No que tange às publicações em uma perspectiva temporal, conforme se observa no Gráfico 1, após uma (1) publicação em 2013 e nenhuma (0) em 2014, de 2015 em diante se observa a manutenção das publicações sobre o assunto, com uma (1) publicação em 2016, um pico em 2017, com quatro (4) artigos, e novamente uma (1) em 2018. 0 fato de 2018 ter contabilizado apenas um (1) artigo - sugerindo um decrescimento das publicações e um extraordinário ano de 2017 - deve ser visto com cautela, pois a coleta se limitou a artigos publicados até julho de 2018. 
Gráfico 1 - Número de artigos sobre Jornalismo de Dados publicados por ano

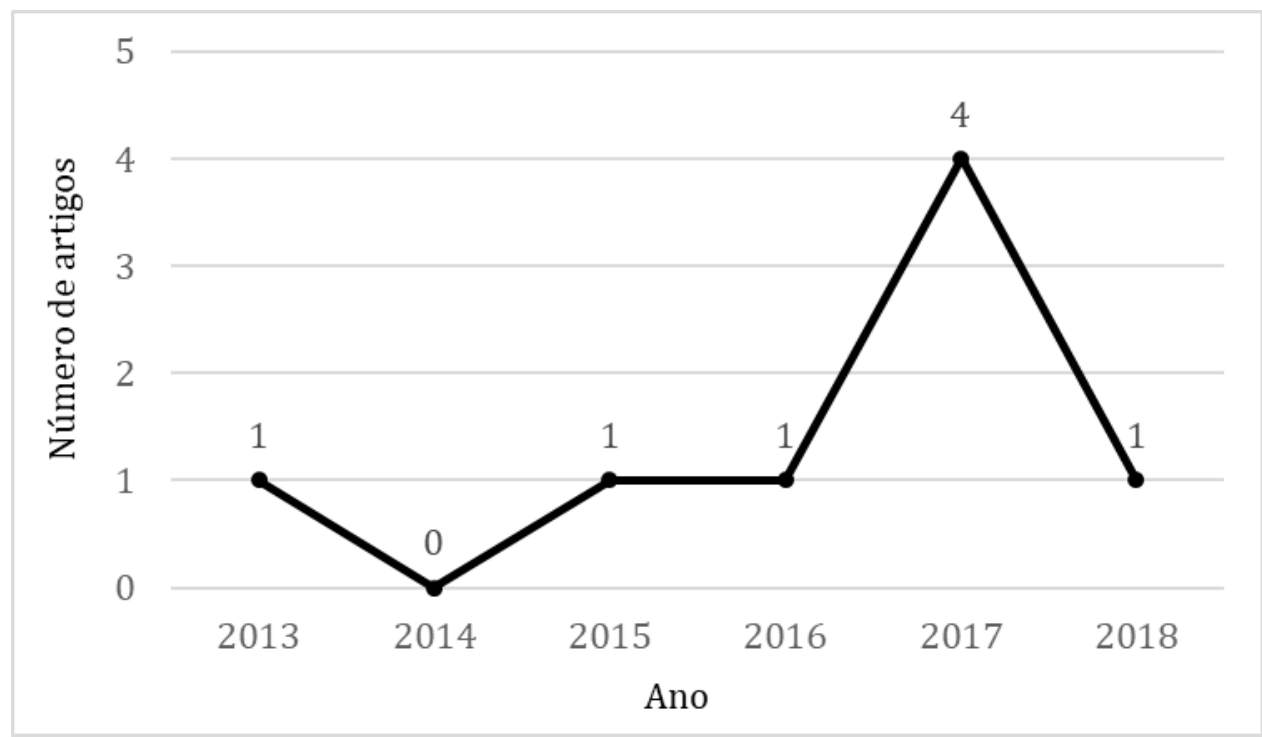

Fonte: Dados da pesquisa.

Corroborando essa leitura, na análise das dissertações e teses (seções 4 e 5), ver-se-á que houve uma coincidência temporal e também de autores, indicando a manutenção e o aumento do interesse sobre o tema nos últimos anos, com um crescimento expressivo em 2016 e 2017 - tendo em vista ainda que estes foram os últimos anos considerados de forma integral no caso artigos, sendo os dados de 2018 limitados à coleta até julho deste ano, e, no caso das dissertações e teses, limitados a novembro de 2017 (devendo-se ter em conta ainda um possível delay, que pode resultar em subnotificação, quanto à atualização dos dados de dissertações e teses na BDTD do IBICIT e no Catálogo de Teses e Dissertações da CAPES).

\subsection{Palavras-chave}

Entre as palavras-chave, além da referência genérica ao Jornalismo, com três (3) ocorrências, e ao Jornalismo de Dados, com seis (6) ocorrências - e também aos seus nomes alternativos: Jornalismo Digital em Base de Dados e Jornalismo guiado por dados, com uma (1) ocorrência para cada -, encontraram-se ainda as seguintes palavraschave: Cibercultura; Comunicação; Ensino de Jornalismo; Imaginário; Jornalismo de Precisão; Jornalismo Digital; Jornalismo Investigativo; Jornalismo Local; Linguagem; Mídia Local; Narrativa Transmídia; Reportagem; além de menções a Damian Radcliffe e Philip Meyer, à Revista Realidade e a casos ocorridos na Alemanha e na Grécia, cada qual com uma (1) ocorrência, totalizando vinte-uma (21) palavras-chave diferentes nos oito (8) artigos em revisão. 
Entre outros fatores, as palavras-chave indicam relações com outros subcampos do Jornalismo (Investigativo, Digital, de Precisão etc.) - o que se subentende tendo em vista as menções a Philip Meyer, precursor do Jornalismo de Precisão e da RAC, e a Damian Radcliffe, que é referência em Jornalismo Digital (e autor de um dos artigos em revisão), mostrando a convergência de assuntos e de intelectuais de referência -, com outros temas - inclusive investigações da Comunicação e do Jornalismo já consagradas (Comunicação; Linguagem; Narrativa transmídia; Jornalismo local; Mídia local), e outras mais contemporâneas (como estudos de Cibercultura) -, e com o Ensino de Jornalismo.

Com isso, conclui-se que tais relações demostram a abrangência do Jornalismo de Dados no campo da Comunicação e no subcampo do Jornalismo.

\subsection{Síntese dos artigos}

Dentre os artigos analisados, 75\% apresentam um histórico do Jornalismo de Dados, e a maioria dos autores procura conceituar e apresentar exemplos de como este vem sendo incorporado, assim como debater o papel dos jornalistas nesse contexto, ressaltando aí as novas habilidades exigidas dos profissionais no manuseio de dados digitais. Muitos artigos ressaltam ainda a importância da visualização dos dados na composição de uma narrativa atraente e inteligível, mas não somente por isso, e sim por conceituação, esta característica deve ser considerada como parte da definição de Jornalismo de Dados - o que se nota mais claramente a partir da síntese dos artigos que se segue.

Barbosa e Torres (2013, p. 153) veem o "Jornalismo Digital em Base de Dados" como um campo em expansão e o definem como um jornalismo "produzido com dados", e de "uma variedade de fontes públicas e privadas - inclusive as próprias organizações jornalísticas de mainstream", e que podem ser apresentados em sua "forma mais bruta" ou ainda "segundo padrões de design e formatos diversos para a narrativa jornalística", visando a uma "melhor apresentação e compreensão do leitor/usuário, do público".

As francesas Charbonneaux e Gkouskou-Giannakou (2015) falam de números e de dados nos processos produtivos e da necessidade de rotinização da produção jornalística em prol do Jornalismo de Dados. As autoras destacam que o Jornalismo de Dados segue a linha da RAC, caracterizada pelo uso de complexos métodos de trabalho e pela colaboração entre jornalistas, técnicos e acadêmicos de áreas distintas, entretanto, mantendo os modelos já consagrados do Jornalismo Investigativo. As autoras fazem ainda uma comparação entre os casos grego e alemão, contextualizando o processo de consolidação do Jornalismo de Dados nesses países, o que ajuda a entendermos o aumento recente da sua importância no Brasil, 
dado o contexto de contestação política que marca a conjuntura destes países, embora em diferentes aspectos e medidas. Assim, os resultados da pesquisa sugerem que o subcampo do Jornalismo de Dados ganha mais força em contextos políticos em que há uma crise de representação ou em que há uma desconfiança dos cidadãos em relação a seus governos, ou ainda em que há uma aparente estabilidade política, maquilada pela falta de transparência pública - sendo esta evidenciada pelo uso cidadão e investigativo do Jornalismo de Dados.

Ao tentarem categorizar e conceituar o Jornalismo de Dados, Mancini e Vasconcellos (2016, p. 73) destacam que o Jornalismo de Dados aparece em um contexto de disseminação da cultura de dados abertos, atendendo ao princípio democrático do open government, o que altera a natureza do trabalho jornalístico, que assim se funde com “[...] os princípios da cultura de dados abertos" e com "o trabalho computacional". Os autores também buscaram diferenciar a "reportagem com dados" da "reportagem de dados". Segundo eles, a diferença principal é que a primeira se apropria dos dados de forma ilustrativa, mais superficial; já, na segunda, os dados são sua razão de existir e o próprio fundamento da pauta, conduzindo a reportagem. Mancini e Vasconcellos (2016) apresentam as três dimensões da reportagem no Jornalismo de Dados: investigativa (envolve a coleta, extração e organização dos dados); interpretativa (envolve a análise de dados e a argumentação por parte do jornalista ou dos participantes da reportagem); comunicativa (envolve a forma de expor os dados, a estética e a visualização, enfim, a comunicação com o leitor).

Convergindo em termos da abordagem, Zibordi (2018) se baseou nas três dimensões do Jornalismo de Dados tal como definidas por Mancini e Vasconcellos (2016), analisando o caso da revista Realidade (publicada entre 1966 e 1973), destacando os aspectos de uma narrativa baseada em estatísticas, porém, ele considerou seu conteúdo como duvidoso e tendencioso.

Na entrevista feita por Gehrke e Mielniczuk com Philip Meyer (2017), o criador do Jornalismo de Precisão, as entrevistadoras também conceituaram o Jornalismo de Dados: envolve a coleta, análise e visualização de dados, reúne aspectos do Jornalismo de Precisão, da RAC e do Jornalismo Computacional, e mantém relação com a "transparência pública", partindo de bases de dados governamentais e estatísticas (enquanto dados produzidos para o Estado). Introduzindo a entrevista, as entrevistadoras chamam atenção para uma antiga fala de Meyer, que, atualmente, comprovou-se: escrever bem não seria a única atribuição demandada dos jornalistas, pois seria necessário também entender e organizar dados.

Já Mielniczuk e Träsel (2017) abordam os desafios do ensino do Jornalismo de Dados e trazem exemplos do exterior e do Brasil, salientando também como sua aplicabilidade se desenvolve na prática. Apontam-no como uma inovação dentro do Jornalismo e definem-no 
como o jornalismo praticado a partir de fontes documentais e bases de dados na apuração de informações que comporão a reportagem. Além deste, outro ponto importante destacado é a orientação do ensino para a prática do Jornalismo de Dados e não tanto pela teoria, com o ensino prático da coleta, análise e apresentação dos dados obtidos em bancos públicos.

Radcliffe (2017) dá exemplos de como o Jornalismo de Dados tem sido utilizado nos EUA e sugere formas de aplicabilidade. Destacando a importância do Jornalismo de Dados voltado a questões locais, o autor arfirma que esse é também o foco dos jornalistas, e não apenas a utilização de grandes bases nacionais. Argumenta ainda que o Jornalismo de Dados é interessante para o público, que tem valor-notícia, e ressalta o seu caráter cidadão, pois os dados em si não são suficientes para a produção de uma reportagem, mas podem ser a base ou também o complemento de um texto informativo de interesse público.

Por fim, Luciana Renó, Renó e Corrêa (2017) avaliam quais são os desafios dos profissionais do jornalismo na contemporaneidade e buscam conceituar o Jornalismo de Dados, aproximando-o e o diferenciando de outros campos. Para eles, o Jornalismo de Dados é um aprofundamento nos dados, reunindo técnicas específicas das ciências exatas e sociais, e também uma adaptação de diferentes métodos jornalísticos (RAC, Jornalismo Investigativo e Jornalismo de Precisão), favorecendo um jornalismo cidadão e que possibilita ao leitor se inteirar aos dados e à informação públicos, construindo uma sólida opinião própria.

\subsection{Trajetórias dos autores}

A partir dos conteúdos dos artigos, não é possível identificar núcleos de excelência, por isso a análise do currículo dos autores dos artigos foi importante para o mapeamento de grupos e projetos de pesquisa que compõem o subcampo científico do Jornalismo de Dados no Brasil. Nesse sentido, vale destacar sinteticamente as trajetórias de alguns autores.

Destacam-se os autores ligados à UFRGS: a professora Luciana Pellin Mielniczuk (falecida) estudava o Jornalismo Digital desde 1995, e desde 2003 coordenava projetos de pesquisa sobre a Lei de Acesso à Informação (LAI), sobre webjornalismo, ciberjornalismo e sobre jornalismo e redes sociais, tendo recentemente coordenado o projeto De práticas inovadoras e criativas no jornalismo em redes digitais às suas formas de abordagem pelo pensamento acadêmico. Ela orientou Marília Gehrke, com quem realizou a entrevista com Philip Meyer (2017), que à época fazia Mestrado em Comunicação e Informação na UFRGS, onde ambas integravam o Grupo de Pesquisa em Jornalismo Digital (JorDi) e onde Gehrke defendeu a dissertação $O$ uso de fontes documentais no jornalismo guiado por dados. Hoje, no mesmo programa, Gehrke cursa seu doutorado, com pesquisa intitulada Como os dados são 
transformados em conhecimento no jornalismo explicativo do Nexo. Também da UFRGS, o professor Marcelo Träsel - coautor da professora Luciana (MIELNICZUK; TRÄSEL, 2017) em artigo aqui revisado - publicou trabalhos voltados à internet e ao digital desde a década de 1990 e tem desenvolvido diversos trabalhos sobre Jornalismo de Dados, inclusive com a colaboração no Manual de Jornalismo de Dados 1.0 (GRAY; BOUNEGRU; CHAMBERS, 2014) reeditado em português pela Associação Brasileira de Jornalismo Investigativo (Abraji).

Outra autora a se destacar é a professora da UFBA Suzana Oliveira Barbosa, que é doutora em Comunicação e Cultura Contemporânea, coordenou o projeto Laboratório de Jornalismo Convergente e tem papel de destaque no Grupo de Pesquisa em Jornalismo OnLine (GJOL); fez doutorado sanduíche com foco em Jornalismo Digital na Universidade da Beira Interior, em Portugal, tendo recebido o Prêmio Adelmo Genro Filho de melhor tese de doutorado em Jornalismo, com o trabalho intitulado Jornalismo Digital em Bases de Dados (JDBD): um paradigma para produtos jornalísticos digitais dinâmicos, de 2007, que foi uma pesquisa pioneira no Brasil. A autora fez ainda estágio pós-doutoral na Universidade de Santiago de Compostela, onde integrou como pesquisadora o projeto Jornalismo na internet: um estudo comparado dos cibermeios Brasil/Espanha.

Um caso mais recente de tese sobre o assunto é o de Luciana Tarlá Lorenzi Renó, que, em 2016, doutorou-se em Comunicação pela Universidade Complutense de Madri na Espanha, com a tese Periodismo de datos y narrativa transmedia en la era del Big Data, e hoje é membro da Cátedra Latino-Americana de Narrativa Transmídia e do Mobilab Research, projeto ligado à Unesp, em que coordena a produção de Jornalismo de Dados em ambientes multiplataforma móveis. Desenvolve também pesquisa pós-doutoral sobre Jornalismo de Dados na Escola de Comunicações e Artes da Universidade de São Paulo (ECA/USP), sob supervisão de Elizabeth Nicolau Saad Corrêa - coautora do artigo em revisão (RENÓ; RENÓ; CORRÊA, 2017). Vale destacar ainda que Corrêa é pesquisadora especializada no Jornalismo Digital e que foi professora visitante na Oslo Metropolitan University na Noruega, no ano de 2018, onde integrou o grupo de pesquisa Digital Journalism Studies.

Por fim, destaca-se Fábio Souza Vasconcellos, mestre em Comunicação e doutor em Ciência Política, que, entre 2017 e 2018, foi pesquisador e coordenador adjunto do Centro de Tecnologia e Sociedade da Fundação Getúlio Vargas. Ele é docente do Departamento de Jornalismo da UERJ e também da ESPM-RJ, onde, entre 2013 e 2015, coordenou o projeto intitulado Jornalismo guiado por dados e democracia: as novas ferramentas de investigação jornalística e sua contribuição para o processo de accountability político no Brasil. 


\section{Dissertações sobre Jornalismo de Dados}

Majoritariamente, os títulos das sete (7) dissertações remetem aos aspectos técnicos e instrumentais do Jornalismo de Dados, apropriados tanto na prática profissional, quanto nos modelos de reportagem baseada em dados - seja em termos da extração, organização ou curadoria de dados.

Quadro 2 - Dissertações que trabalharam o Jornalismo de Dados

\begin{tabular}{|c|c|c|c|}
\hline Título & Autor(a) & Orientador(a) & Universidade \\
\hline $\begin{array}{l}0 \text { curador de informação em } \\
\text { produtos agregadores de } \\
\text { notícias }\end{array}$ & Vitor Torres & $\begin{array}{c}\text { Suzana Oliveira } \\
\text { Barbosa }\end{array}$ & UFBA \\
\hline $\begin{array}{l}\text { A reportagem com base na } \\
\text { extração, análise e } \\
\text { visualização de dados }\end{array}$ & $\begin{array}{c}\text { Anna Barbara } \\
\text { Medeiros }\end{array}$ & $\begin{array}{c}\text { Rita de Cássia } \\
\text { Romeiro Paulino }\end{array}$ & UFSC \\
\hline $\begin{array}{l}\text { Organização e } \\
\text { gerenciamento de conteúdos } \\
\text { jornalísticos na web } \\
\text { semântica }\end{array}$ & $\begin{array}{l}\text { Iuri Lammel } \\
\text { Marques }\end{array}$ & $\begin{array}{l}\text { Luciana Pellin } \\
\text { Mielniczuk }\end{array}$ & UFSM \\
\hline $\begin{array}{l}\text { Siga os números: introdução } \\
\text { ao uso de dados no } \\
\text { jornalismo de finanças e } \\
\text { negócios }\end{array}$ & Mariana Segala & $\begin{array}{l}\text { Ana Cristina } \\
\text { Menegotto } \\
\text { Spannenberg }\end{array}$ & UFU \\
\hline $\begin{array}{l}\text { Jornalismo de dados na web: } \\
\text { estudo da produção de } \\
\text { sentido na infografia do Blog } \\
\text { do Estadão Dados e do La } \\
\text { Nación Data Blog }\end{array}$ & $\begin{array}{l}\text { Kelly de Conti } \\
\text { Rodrigues }\end{array}$ & $\begin{array}{c}\text { Eliza Bachega } \\
\text { Casadei }\end{array}$ & Unesp \\
\hline $\begin{array}{l}\text { Processos no jornalismo } \\
\text { digital: do Big Data à } \\
\text { visualização de dados }\end{array}$ & $\begin{array}{l}\text { Mayanna } \\
\text { Estevanim }\end{array}$ & $\begin{array}{c}\text { Elizabeth Nicolau } \\
\text { Saad Corrêa }\end{array}$ & USP \\
\hline $\begin{array}{l}\text { Usos e apropriações de } \\
\text { tecnologias no cotidiano do } \\
\text { jornalismo guiado por dados }\end{array}$ & $\begin{array}{c}\text { Matias Sebastião } \\
\text { Peruyera }\end{array}$ & $\begin{array}{l}\text { Luiz Ernesto } \\
\text { Merkle }\end{array}$ & UTFPR \\
\hline
\end{tabular}

Fonte: Dados da pesquisa. 
Destaque para o autor Vitor Torres e para sua orientadora Suzana Barbosa, da UFBA, que aparecem entre os autores dos artigos aqui revisados (BARBOSA; TORRES, 2013); para Elizabeth Nicolau Saad Corrêa, que aparece na coautoria de um dos artigos (RENÓ; RENÓ; CORRÊA, 2017) e como orientadora da tese de Daniela Ramos (2011); e para Luciana Pellin Mielniczuk, por ocasião da orientação da dissertação de Iuri Marques (2011), então vinculada à UFSM (Universidade Federal de Santa Maria), mas que aparece já vinculada à UFRGS no artigo - Mielniczuk e Träsel (2017) - e na entrevista com Philip Meyer (2017), considerados nesta revisão.

Entre as instituições, cada qual está vinculada a apenas uma (1) dissertação, mas é de se destacar que UFBA, UFRGS, Unesp e USP aparecem também entre os vínculos dos autores dos artigos, o que indica a possibilidade de haver (ou de estarem se formando) núcleos de excelência em Jornalismo de Dados nessas IES - ou que, pelo menos, possuem linhas abrangentes em subcampos relacionados, como linhas ligadas ao Jornalismo Digital, por exemplo. Como novidade, mas reforçando ainda a potência das regiões Sul e Sudeste na produção sobre o tema aqui revisado, com vínculo a uma (1) dissertação cada, aparecem: Universidade Federal de Santa Catarina (UFSC), Universidade Federal de Uberlândia (UFU) e Universidade Tecnológica Federal do Paraná (UTFPR).

\subsection{Série histórica}

Conforme se observa no Gráfico 2, a primeira dissertação relacionada ao Jornalismo de Dados data de 2011, sendo a única desse ano. Não houve produção em 2012; em 2013, houve uma (1); nenhuma (0) em 2014; uma (1) em 2015; em 2016, observa-se um pico no número de defesas, com três (3) dissertações; retornando, em 2017, para uma (1).

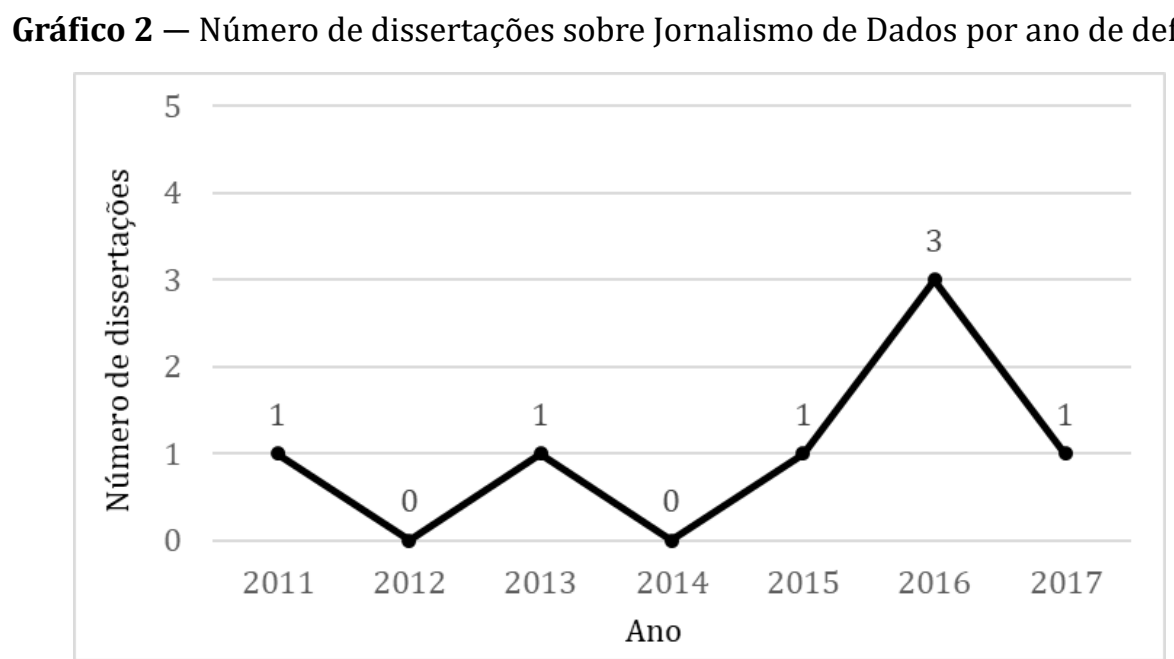

Fonte: Dados da pesquisa. 
A análise dessa série histórica sugere que o assunto ganha relevância atualmente, o que é corroborado pela maior constância na publicação sobre o tema a partir de 2015, pelo pico de produções em 2016, e, de modo relacionado, também pela alta na publicação de artigos em 2017, como mostramos na seção anterior, podendo caracterizar uma tendência (ou pelo menos uma alta conjuntural). Quanto ao fato de termos registrado apenas uma (1) dissertação em 2017, deve-se ter em conta que nossa coleta de dados foi feita em novembro deste mesmo ano e que pode haver um delay na atualização da BDTD do IBICIT e do Banco de Dissertações e Teses da CAPES, o que pode ter acarretado em subnotificação dos casos.

Relacionando essa análise da série histórica com o contexto dos programas em que foram produzidas as dissertações, conclui-se, que, como área de pesquisa, o Jornalismo de Dados ainda é pouco expressivo nas pós-graduações brasileiras, de modo que não se notam linhas de pesquisa especializadas. Mas seu crescimento recente, ainda que tímido, associado à formação de professores pioneiros aptos a orientarem trabalhos de graduação na área (ao considerar esses mestres como potenciais professores de graduação), sugere um incipiente processo de consolidação deste subcampo na academia.

\subsection{Palavras-chave}

Dentre as palavras-chave encontradas, as que mais ocorrem ou demonstram relação com o Jornalismo de Dados são: Jornalismo; Jornalismo Digital; Big Data e Visualização de Dados. Essas ocorrências não são surpresa, já que estas palavras-chave estão intrinsecamente relacionadas às dimensões do Jornalismo de Dados, cumprindo aqui, portanto, o seu papel de indexação das buscas sobre o tema e temáticas relacionadas.

\subsection{Síntese das dissertações}

Marques (2011) relacionou Jornalismo Digital em Base de Dados e o funcionamento das tecnologias empregadas na Web Semântica. A pesquisa apresentou caráter exploratório e empregou como estratégia de investigação o estudo de caso, especificamente dos sites da BBC World Cup 2010 e da BBC Wildlife.

No caso de Torres (2013), o objeto de pesquisa foi o desenvolvimento do produto agregador de notícias e da personagem que faz a curadoria da informação noticiosa, tanto o curador humano, quanto o não humano. Amparada em teorias do jornalismo e trazendo o paradigma do Jornalismo Digital em Base de Dados (JDBD) como marco teórico e conceitual, 
a pesquisa de Torres (2013) combinou concepções próprias aos conceitos de "curadoria de informação na internet" e de "agregação de notícias na internet".

Peruyera (2015) abordou como, cotidianamente, os profissionais do jornalismo se apropriam de artefatos e tecnologias computacionais para trabalhar com Jornalismo Guiado por Dados e, em especial, com visualizações de dados.

Medeiros (2016) tratou das maneiras pelas quais os jornalistas podem integrar as técnicas de extração, análise e visualização de dados na elaboração e na apresentação da reportagem on-line, bem como nos processos do trabalho jornalístico como um todo.

Rodrigues (2016) busca compreender a emergência da infografia em base de dados no Jornalismo Digital, a partir da investigação da estruturação discursiva de dados textuais e imagéticos. A análise empírica foca os casos do Blog Estadão Dados e La Nación Data Blog.

Estevanim (2016) problematiza a visualização de dados no jornalismo que é feito no Brasil e, a partir da análise empírica de veículos que usam o Jornalismo de Dados em seus portais e com base em conceitos e práticas relacionados ao Jornalismo de Dados, demonstra como este proporcionaria diferenciais relevantes na visualização de dados.

Por fim, Segala (2017) apresenta o percurso da pesquisa no desenvolvimento de um manual, em formato de um e-book, sobre a aplicação de técnicas, práticas e ferramentas de Jornalismo de Dados na cobertura jornalística de economia, em trabalho intitulado Siga os números: introdução ao uso de dados no jornalismo de finanças e negócios. Nessa dissertação, ela abordou o Jornalismo de Dados como uma tendência emergente ligada às implicações técnicas, sociais e institucionais do advento do digital e das redes, e ao crescimento de bases de dados ao alcance dos cidadãos.

\section{Teses sobre Jornalismo de Dados}

Os títulos das seis (6) teses em revisão chamam a atenção para a relação entre o Jornalismo de Dados e a incorporação de números nas produções e narrativas jornalísticas, assim como para as mudanças nas rotinas produtivas e no perfil dos profissionais - cada vez mais de tipo colaborativo e interdisciplinar.

Quadro 3 - Teses que trabalharam o Jornalismo de Dados

\begin{tabular}{|c|c|c|c|}
\hline Título & Autor & Orientador & Universidade \\
\hline $\begin{array}{c}\text { Jornalismo digital em base de } \\
\text { dados (JDBD): um paradigma } \\
\text { para produtos digitais } \\
\text { dinâmicos }\end{array}$ & $\begin{array}{c}\text { Suzana Oliveira } \\
\text { Barbosa }\end{array}$ & $\begin{array}{c}\text { Marcos Silva } \\
\text { Palacios }\end{array}$ & UFBA \\
\hline
\end{tabular}




\begin{tabular}{|c|c|c|c|}
\hline $\begin{array}{c}\text { Entrevistando planilhas: } \\
\text { estudo das crenças e do ethos } \\
\text { de um grupo de profissionais } \\
\text { de jornalismo guiado por } \\
\text { dados no Brasil }\end{array}$ & $\begin{array}{c}\text { Marcelo Ruschel } \\
\text { Träsel }\end{array}$ & Francisco Rüdiger & PUCRS \\
\hline $\begin{array}{c}\text { Jornalismo de (im)precisão: o } \\
\text { conhecimento matemático e a } \\
\text { apuração de números }\end{array}$ & $\begin{array}{c}\text { Marco Antônio } \\
\text { Gehlen }\end{array}$ & $\begin{array}{c}\text { Beatriz Corrêa } \\
\text { Pires Dornelles }\end{array}$ & PUCRS \\
\hline $\begin{array}{c}\text { A colaboração no jornalismo: } \\
\text { do Arizona project aos } \\
\text { Panama papers }\end{array}$ & $\begin{array}{c}\text { Carla Miranda B. de } \\
\text { Freitas }\end{array}$ & $\begin{array}{c}\text { Cecilia Almeida } \\
\text { Salles }\end{array}$ & PUC-SP \\
\hline $\begin{array}{c}\text { Formato: condição para a } \\
\text { escrita do jornalismo digital } \\
\text { de bases de dados. Uma } \\
\text { contribuição da semiótica da } \\
\text { cultura. }\end{array}$ & $\begin{array}{c}\text { Daniela Osvald } \\
\text { Ramos }\end{array}$ & $\begin{array}{c}\text { Elizabeth Nicolau } \\
\text { Saad Corrêa }\end{array}$ & USP \\
\hline $\begin{array}{c}\text { Jornalismo transnacional: } \\
\text { prática, método e conceito }\end{array}$ & $\begin{array}{c}\text { Ben Hur Demeneck } \\
\text { Eugênio Bucci }\end{array}$ & USP \\
\hline
\end{tabular}

Fonte: Dados da pesquisa.

Destacam-se: a tese de Suzana Barbosa (2007), pesquisadora que também aparece na presente revisão como orientadora de dissertação (TORRES, 2013) e autora principal de artigo (BARBOSA; TORRES, 2013); a orientação de Elizabeth Corrêa, que aparece também como orientadora de dissertação (ESTEVANIM, 2016) e coautora de artigo (RENÓ; RENÓ; CORRÊA, 2017); e a tese de Marcelo Träsel (2014), o qual aparece como coautor de um dos artigos aqui revistos (MIELNICZUK; TRÄSEL, 2017).

Entre as IES, em número de teses, com vínculo a duas (2) cada, destacam-se a USP e a Pontifícia Universidade Católica do Rio Grande do Sul (PUCRS). É de se pontuar também que USP e UFBA - esta última, com uma (1) tese - aparecem entre os vínculos tanto dos autores dos artigos, quanto dos autores das dissertações e teses. De novidade, aparece a Pontifícia Universidade Católica de São Paulo (PUC-SP), com uma (1) tese.

\subsection{Série histórica}

Conforme se observa no Gráfico 3, entre 2007 e 2016, foram defendidas um total de seis (6) teses relacionadas ao Jornalismo de Dados, com um maior número de defesas em 2016, ano em que se deram três (3) defesas, mesmo número de defesas verificado entre as 
dissertações para este ano. A primeira defesa de tese ocorreu em 2007, ano em que, assim como em 2011 e 2014, houve apenas uma (1) defesa. De 2008 a 2010 e nos anos de 2012, 2013 e 2015 não foram registradas defesas de teses nas bases de dados pesquisadas (BDTD e Catálogo de Teses e Dissertações da CAPES). Note-se que, em comparação com as datas de publicação do primeiro artigo sobre Jornalismo de Dados, 2013, - considerando-se que nos estratos Qualis mais altos está também a maioria das revistas mais antigas, o que evita em muito a chance de um lapso imprevisto na coleta - e da primeira dissertação, 2011, a data de publicação da primeira tese é bem anterior, 2007. Isso coloca os estudos de doutorado como "pontas de lança" na constituição do subcampo do Jornalismo de Dados no Brasil.

Gráfico 3 - Número de teses sobre Jornalismo de Dados por ano de defesa

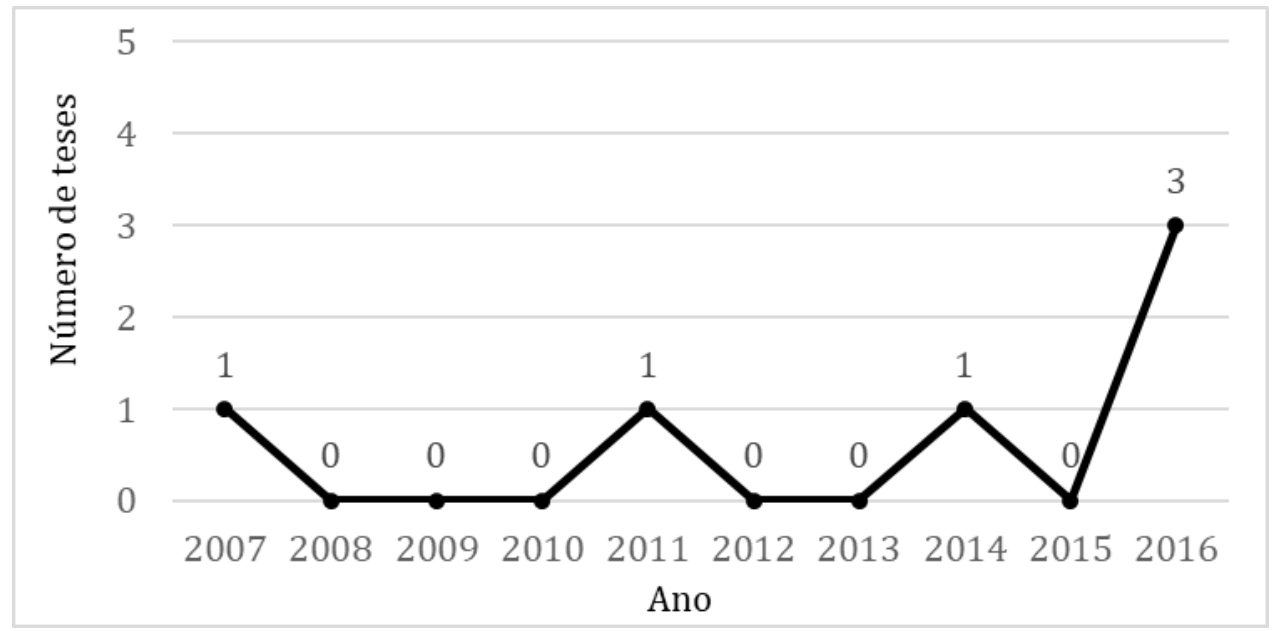

Fonte: Dados da pesquisa.

Além do pico de defesas em 2016, a diminuição do intervalo entre as publicações (2007-2011-2014-2016, respectivamente, intervalos de três anos, dois anos e de um ano) sugere que o assunto, mais do que recorrente, vem se consolidando como área de pesquisa, contando com a realização de estudos densos e profundos (como teses de doutorado), o que indica também um aumento na relevância do tema do Jornalismo de Dados para o campo da Comunicação, e ainda um provável aumento na oferta de professores que poderão orientar pesquisas em Jornalismo de Dados em nível de mestrado e de doutorado.

\subsection{Palavras-chave}

Dentre as palavras-chave encontradas, a que mais ocorre é: Jornalismo Digital; mais dispersamente, ocorrem outras palavras-chave relacionadas a métodos de pesquisa, a dados e à prática jornalística - tais como: apuração, objetividade, notícia -, ou mesmo a outros subcampos do Jornalismo, que são muito próximos do Jornalismo de Dados e às vezes até se 
confundem com ele, como: Jornalismo de Precisão, Jornalismo Investigativo, Jornalismo

Computacional etc. A análise das palavras-chave indica ainda que as teses não se voltam específica e exclusivamente ao Jornalismo de Dados (o que também ocorre entre os artigos e dissertações), mas isso se deve até mesmo ao ineditismo de produção nacional no tema, levando os estudos a se apoiarem em áreas correlatas já mais desenvolvidas, e, por isso também, as pesquisas em si não possuem uma centralidade temática ou de abordagem - o que mostra novamente a abrangência do Jornalismo de Dados.

\subsection{Síntese das teses}

Barbosa (2007) foi pioneira no Jornalismo de Dados no Brasil. Sua premiada tese teve como preocupação central identificar e compreender as transformações do Jornalismo Digital advindas com a crescente utilização de bases de dados nesse meio. Segundo a autora, as bases de dados são um aspecto-chave, que inspira a designação do próprio paradigma do Jornalismo Guiado por Dados, agora em uma etapa de transição entre a terceira e a quarta fases de sua evolução para o Jornalismo Digital, que ela identifica como o paradigma do Jornalismo Digital em Base de Dados (JDBD). Feita essa transição, a própria Web se tornará uma grande base de dados, de cujo conteúdo o jornalismo usufruirá - daí o entendimento do Jornalismo Guiado por Dados como uma parte do paradigma do JDBD.

Ramos (2011) apresenta um estudo teórico sobre como o formato serve de estrutura para as linguagens digitais, que são escritas com signos informáticos. Para isso, ela utilizou ferramentas teóricas da Semiótica da Cultura, tendo explorado textos digitais de informação jornalística. A noção do design foi central aos seus argumentos. A autora trabalhou com a perspectiva de que o Jornalismo Digital em Bases de Dados (JDBD) é um texto da cultura, e que, por isso, atualiza-se ao seu tempo, mantendo os princípios da representação numérica, da modularidade, da automatização, da variabilidade e da transcodificação.

Tendo em foco a prática profissional, Träsel (2014) procurou investigar os valores, as crenças e a conduta dos profissionais de Jornalismo Guiado por Dados no Brasil, a partir de observação participante realizada junto à equipe do Estadão Dados, na redação do jornal $O$ Estado de S. Paulo, e de entrevistas abertas com informantes considerados relevantes à formação e difusão desta nova especialidade do jornalismo.

Com o intuito de verificar o modo como números e dados têm sido utilizados nas matérias jornalísticas, bem como a importância que têm adquirido nessas matérias, Gehlen (2016) propôs em sua tese um estudo investigativo sobre os números e os dados na prática profissional de reportagem, a partir de diálogo estabelecido com as teorias do Jornalismo de 
Precisão, do Jornalismo Investigativo e do Jornalismo de Dados, sinalizando as competências matemáticas demandadas na prática do jornalismo contemporâneo.

Demeneck (2016) trabalhou o conceito de jornalismo transnacional (in. cross border journalism; es. periodismo transfronteirizo; din. journalistik over grænser), que ganhou maior visibilidade na década de 2010, a partir de séries como a OffshoreLeaks e o SwissLeaks, que estabeleceram redes de investigação colaborativa entre equipes de diferentes países e em torno de temas de relevância regional ou mundial. $\mathrm{O}$ autor pretendeu mapear os pioneiros dessa nova prática jornalística, que cada vez mais atrai profissionais e interessa às redações.

Por fim, Freitas (2016) analisou casos exemplares que evidenciaram a importância do Jornalismo de Dados na contemporaneidade, como: o Arizona Project, desenvolvido ainda nos anos 1970 e considerado o primeiro trabalho de atuação jornalística conjunta em grande escala, e nos Panama Papers, investigação que reuniu quase 400 profissionais, de 76 países, em torno do maior vazamento de dados até então, passando pelos casos WikiLeaks e Snowden e pelo surgimento de organizações comunicacionais como a ProPublica, nos EUA. Freitas (2016) aborda também a prática cotidiana nas redações e a relação de colaboração entre jornalistas de diferentes veículos, fato que ele apresenta como tendência e que teria sido impulsionado pela característica colaborativa do Jornalismo de Dados.

\section{Considerações finais}

Em suma, esta revisão é um testemunho do surgimento da pesquisa em Jornalismo de Dados no Brasil e, embora não possibilite uma visão completa, visto que publicações em livros e periódicos importantes não foram contempladas, ${ }^{1}$ permite uma visão panorâmica em que identificamos trabalhos evidenciando a emergência deste subcampo do Jornalismo, dentro do grande campo científico da Comunicação.

Despontando no ano de 2007, as produções relacionadas ao Jornalismo de Dados vão aumentando em número e em frequência, atingindo o seu clímax em 2016 e 2017, com muitos artigos, dissertações e teses sendo publicados - dos oito (8) artigos encontrados, quatro (4) foram publicados em 2017; das sete (7) dissertações, três (3) foram defendidas em 2016; e, das seis (6) teses, três (3) foram defendidas em 2016.

Além de herdar o desenvolvimento de áreas correlatas, como a RAC e o Jornalismo de Precisão, e de coproduzir o avanço técnico do Jornalismo Digital, o movimento vislumbrado se dá em concomitância com eventos internacionais e se relaciona ao desenvolvimento de

\footnotetext{
Isso se explica até mesmo por questões de indexação: os metadados públicos dessas publicações não eram homogêneos o bastante para se produzir uma revisão sistemática (por exemplo, a indisponibilidade pública das avaliações Qualis Livros e a falta de outras bases nacionais de indexação de livros ou mesmo artigos em publicações dos estratos B2 em diante, que nem sempre apresentavam resumos e palavras-chave, entre outros problemas técnicos).
} 
importantes ferramentas de accountability e de redes colaborativas de Jornalismo de Dados e de Jornalismo Investigativo - como nos casos Swiss Leaks e Panama Papers, por exemplo.

Em sintonia com o cenário internacional, no Brasil da atualidade, a crise econômica, os escândalos de corrupção, o clima golpista, o contexto político instável e a desconfiança da população em relação aos governos coincidem com o aumento das iniciativas em Jornalismo de Dados e Jornalismo Investigativo, e, com isso, a demanda por mais acesso à informação e mais transparência dos dados públicos podem ter ajudado a impulsionar as pesquisas aqui revisadas. Porém, o que se pode afirmar a partir da presente revisão é que, embora às vezes de forma instrumental ou combinadas a outras perspectivas, a articulação e a formação de pesquisadores em torno do Jornalismo de Dados têm consolidado a produção acadêmica e científica deste subcampo do Jornalismo (e do grande campo da Comunicação) no país.

\section{Referências}

BARBOSA, Suzana. Jornalismo digital em base de dados (JDBD): um paradigma para produtos jornalísticos digitais dinâmicos. 2007. Tese (Doutorado em Comunicação e Cultura Contemporâneas) - Programa de Pós-Graduação em Comunicação e Cultura Contemporâneas, Universidade Federal da Bahia, Salvador, 2007.

BARBOSA, Suzana; TORRES, Vitor. O paradigma "Jornalismo Digital em Base de Dados": modos de narrar, formatos e visualizações para conteúdos. Galáxia, São Paulo, v. 13, n. 25, p. 152-164, 2013.

BOURDIEU, Pierre. 0 campo científico. In: ORTIZ, R. (org.). Pierre Bourdieu: sociologia. São Paulo: Ática, 1983.

CHARBONNEAUX, Juliette; GKOUSKOU-GIANNAKOU, Pergia. 0 jornalismo de "dados", uma prática de investigação? Um olhar sobre os casos alemão e grego. Brazilian Journalism Research, Brasília, v. 11, n. 2, p. 266-291, 2015.

DEMENECK, Ben Hur. Jornalismo transnacional: prática, método e conceito. 2016. Tese (Doutorado em Estudo dos Meios e da Produção Mediática) - Escola de Comunicações e Artes, Universidade de São Paulo, São Paulo, 2016.

ESTEVANIM, Mayanna. Processos no jornalismo digital: do Big Data à visualização de dados. 2016. Dissertação (Mestrado em Teoria e Pesquisa em Comunicação) - Escola de Comunicações e Artes, Universidade de São Paulo, São Paulo, 2016.

FREITAS, Carla Miranda Barroso de. A colaboração no jornalismo: do Arizona Project aos Panama Papers. 2016. Tese (Doutorado em Comunicação e Semiótica) - Faculdade de Filosofia, Comunicação, Letras e Artes, Pontifícia Universidade Católica de São Paulo, São Paulo, 2016.

GEHLEN, Marco Antônio. Jornalismo de (im)precisão: o conhecimento matemático e a apuração de números. 2016. Tese (Doutorado em Comunicação Social) - Programa de Pós- 
Graduação em Comunicação Social, Pontifícia Universidade Católica do Rio Grande do Sul, Porto Alegre, 2016.

GRAY, Jonathan; BOUNEGRU, Liliana; CHAMBERS, Lucy. Manual de Jornalismo de Dados 1.0. Cidade: editora, 2014. Disponível em: http://datajournalismhandbook.org/pt. Acesso em: 2 out. 2017.

MANCINI, Leonardo; VASCONCELLOS, Fabio. Jornalismo de Dados: conceito e categorias. Fronteiras, São Leopoldo, v. 18, n. 1, p. 69-82, 2016.

MARQUES, IUri Lammel. Organização e gerenciamento de conteúdos jornalísticos na web semântica. 2011. Dissertação (Mestrado em Comunicação) - Programa de PósGraduação em Comunicação, Universidade Federal de Santa Maria, Santa Maria, 2011.

MEDEIROS, Anna Barbara. A reportagem com base na extração, análise e visualização de dados. 2016. Dissertação (Mestrado em Jornalismo) - Programa de Pós-Graduação em Jornalismo, Universidade Federal de Santa Catarina, Florianópolis, 2016.

MEYER, Philip. Philip Meyer, the outsider who created Precision Journalism. [Entrevista cedida a] Marília Gehrke e Luciana Mielniczuk. Intexto, Porto Alegre, n. 39, p. 4-13, 2017.

MIELNICZUK, Luciana; TRÄSEL, Marcelo. Jornalismo guiado por dados como inovação profissional e seus desafios para a educação. Contemporânea, Salvador, v. 15, n. 2, p. 609629, 2017.

PERUYERA, Matias Sebastião. Usos e apropriações de tecnologias no cotidiano do jornalismo guiado por dados. 2015. Dissertação (Mestrado em Tecnologia e Sociedade) Programa de Pós-Graduação em Tecnologia, Universidade Tecnológica do Paraná, Curitiba, 2015.

RADCLIFFE, Damian. A importância dos dados para o jornalismo local. Comunicação \& Educação, São Paulo, v. 22, n. 1, p. 85-97, 2017.

RAMOS, Daniela Osvald. Formato: condição para a escrita do jornalismo digital de bases de dados: uma contribuição da semiótica da cultura. 2011. Tese (Doutorado em Interfaces Sociais da Comunicação) - Escola de Comunicações e Artes, Universidade de São Paulo, São Paulo, 2011.

RENÓ, Luciana; RENÓ, Denis; CORRÊA, Elizabeth Saad. Notícia binária: um estudo sobre o Jornalismo de Dados no novo ecossistema midiático. Comunicação \& Sociedade, São Bernardo do Campo, v. 39, n. 1, p. 43-67, 2017.

RODRIGUES, Kelly de Conti. Jornalismo de dados na web: estudo da produção de sentido na infografia do Blog do Estadão Dados e do La Nación Data Blog. 2016. Dissertação (Mestrado em Comunicação) - Faculdade de Arquitetura, Artes e Comunicação, Universidade Estadual Paulista Júlio de Mesquita Filho, Bauru, 2016.

SEGALA, Mariana. Siga os números: introdução ao uso de dados no jornalismo de finanças e negócios. 2017. Dissertação (Mestrado em Tecnologias, Comunicação e Educação) Programa de Pós-graduação em Tecnologias, Comunicação e Educação, Universidade Federal de Uberlândia, Uberlândia, 2017. 
TORRES, Vitor. 0 curador de informação em produtos agregadores de notícias. 2013. Dissertação (Mestrado em Comunicação e Cultura Contemporâneas) - Programa de PósGraduação em Comunicação e Cultura Contemporâneas, Universidade Federal da Bahia, Salvador, 2013.

TRÄSEL, Marcelo Ruschel. Entrevistando planilhas: estudo das crenças e do ethos de um grupo de profissionais de jornalismo guiado por dados no Brasil. 2014. Tese (Doutorado em Comunicação Social) - Programa de Pós-Graduação em Comunicação Social, Pontifícia Universidade Católica do Rio Grande do Sul, Porto Alegre, 2014.

ZIBORDI, Marcos Antônio. Jornalismo de dados na revista Realidade. E-compós, Brasília, v. 21, n. 3, p. 1-21, 2018.

\title{
The emergence of research on Data Journalism in Brazil
}

\begin{abstract}
This work is a systematic review of articles, theses and dissertations on Data Journalism published in Brazil, and with it we aim to map the main studies, approaches, authors, groups, projects and institutions articulated around that theme. The results indicate that research on that subject is still incipient and recent in Brazil (the first work found dates from 2007), and that its importance has grown, as shown by a significant increase in the number of works published in the years 2016 and 2017. Moreover, we pinpoint authors and institutions that have set themselves as pioneers in that subject in Brazil, having taken the first steps to consolidate Data Journalism as a scientific subfield of Journalism, and, therefore, of Communication.
\end{abstract}

\section{Keywords}

Data Journalism. Data-Driven Journalism. Digital Journalism.

Recebido em 20/01/2019

Aceito em 04/11/2019 